\title{
Environmental Injustice in Siting Nuclear Plants
}

\author{
Mary Alldred and Kristin Shrader-Frechette
}

\begin{abstract}
The mining, fuel enrichment-fabrication, and waste-management stages of the US commercial nuclearfuel cycle have been documented as involving environmental injustices affecting, respectively, indigenous uranium miners, nuclear workers, and minorities and poor people living near radioactive-waste storage facilities. After surveying these three environmental-injustice problems, the article asks whether US nuclear-reactor siting also involves environmental injustice. For instance, because high percentages of minorities and poor people live near the proposed Vogtle reactors in Georgia, would siting new reactors at the Vogtle facility involve environmental injustice? If so, would this case be an isolated instance of environmental injustice, or is the apparent Georgia inequity generally representative of environmental injustice associated with nuclear-reactor siting throughout the US? Providing a preliminary answer to these questions, the article uses census data, paired t-tests, and z-tests to compare each state's percentages of minorities and poor people to the percentages living in zip codes and census tracts having commercial reactors. Although further studies are needed to fully evaluate apparent environmental injustices, preliminary results indicate that, while reactor-siting-related environmental injustice is not obvious at the census-tract level (perhaps because census tracts are designed to be demographically homogenous), zipcode-scale data suggest reactor-related environmental injustice may threaten poor people $(p<0.001)$, at least in the southeastern United States.
\end{abstract}

\section{INTRODUCTION}

$\mathrm{E}$ XAMINING POSSIBLE environmental injustice (EIJ) associated with siting commercial US nuclear reactors is important for at least five reasons.

1. Even when reactors operate normally, statistically significant increases in infant and fetal mortality near US reactors, ${ }_{1}^{1}$ in childhood leukemia near German reactors, ${ }^{2}$ and in cancer near UK reactors, ${ }^{3}$ suggest that (even without any accidents) those living near reactors could face higher health risks. ${ }^{1,4,5}$

2. In the event of a reactor accident, those living nearby also could be most at risk, as suggested by increases in lung cancers and leukemias after the 1979 Three Mile Island, Pennsylvania accident. ${ }^{6}$

Doctoral student Alldred is in the Department of Ecology and Evolution at the State University of New York at Stony Brook, in Stony Brook, New York. Dr. Shrader-Frechette is O'Neill Family Endowed Professor, Department of Biological Sciences and Department of Philosophy, and Director of the Center for Environmental Justice and Children's Health, all at the University of Notre Dame, Notre Dame, Indiana.
3. Minority and poverty-level communities often include higher percentages of women and children, both of whom are more sensitive to ionizing radiation, yet most radiation standards are devised to protect only adult males. 7,8

4. Because indigenous uranium miners, nuclear workers, and minorities and poor people living near radioactive-waste dumps have experienced EIJ (see later paragraphs), it is important to ask whether there also is reactor-siting-related EIJ.

5. Few scholars have addressed this question, although some citizens' groups note higher percentages of minorities or poor people living near nuclear plants, ${ }^{9}$ and some scientists suggest children, minorities, and poverty-level people are more sensitive than others to the roughly 100 radioisotopes routinely emitted by reactors. ${ }^{1,4,5}$

This article first summarizes already-documented cases of nuclear-related EIJ, then briefly surveys the proposed siting of the Vogtle reactors in Georgia, where the utility uses questionable criteria for assessing EIJ. Third, using census data, paired t-tests, and z-tests, the article investi- 
gates whether the apparent EIJ at sites like the Grand Gulf, Mississippi reactor is representative of other US nuclear-siting cases. Although further studies are needed to fully evaluate apparent environmental injustices, the article concludes that, while reactor-siting-related EIJ is not obvious at census-tract levels, zip-code data suggest reactor-related EIJ threatens threaten poor people $(p<$ 0.001), at least in the southeastern United States.

\section{DISCUSSION}

Nuclear generation of electricity involves a complex fuel cycle of at least nine stages: (1) mining uranium; (2) milling it; (3) converting it to uranium hexafluoride, $\mathrm{UF}_{6}$; (4) enriching the $\mathrm{UF}_{6}$; (5) fabricating nuclear fuel; (6) generating electricity; (7) reprocessing spent fuel; (8) interim storing of radioactive waste; and (9) transporting and permanently storing wastes. ${ }^{10}$ Because nuclear power has been used for more than half a century, researchers already have documented (see below) many cases of EIJ in nuclear-fuel-cycle stages (1), (2)-(5), and (9).

At stage (1), mining uranium, in most major uraniumproducing nations of the world (e.g., Canada, Australia, Kazakhstan, Niger, Russia, Namibia, Uzbekistan, United States), indigenous peoples have been harmed either by working in unregulated uranium mines; by exposure to uncontrolled uranium wastes on native lands; or by risky uranium mining/processing on their lands, although they failed to consent to these operations. ${ }^{11}$ In Canada, for instance, all uranium mining is on lands claimed by, or directly affecting, indigenous groups. ${ }^{12,13}$ In the United States, Native-American uranium miners, e.g., Navajos, face 14 times the normal lung-cancer risk, "most" of which has been caused by their uranium-mining, not smoking. ${ }^{14}$ The US government admits that it failed to require uranium-mine ventilation, failed to disclose radiation risks to Navajo miners, and had "no plausible justification" for allowing massive exploitation of Native-American uranium miners. ${ }^{11}$ In 2005, Navajo Nation demanded a moratorium on uranium mining/processing on its lands (a moratorium not honored by the US government) until ongoing damages have been assessed and remedied. These damages include inadequate compensation for radiation-induced disease among native miners, no permanent closure/decontamination of hundreds of uranium-mining/ processing sites that continue to expose native peoples, and no ongoing medical studies of the health status of Native Americans affected by uranium mining. ${ }^{15}$

In stages (2)-(5) of the nuclear fuel cycle, tens of millions of radiation workers, including nearly two million in the United States, ${ }^{16}$ also have faced EIJ. US nuclear-facility owners legally may expose workers to annual radiation doses up to 50 times higher than those allowed for members of the public, ${ }^{17}$ although there is no safe dose of ionizing radiation. ${ }^{7}$ Yet radiation workers typically receive no hazard pay or compensating wage differential. ${ }^{3}$ Often they also do not voluntarily accept dangerous nuclear jobs but take them because of economic necessity, ${ }^{3}$ because government falsification of worker radiation doses has mislead them, ${ }^{18,19}$ or because flawed radiation standards, flawed risk disclosure, and flawed workplace-radiation monitoring cause them to underestimate risks. ${ }^{20}$ Yet the risks are substantial. The International Agency for Research on Cancer (IARC) shows roughly 1 additional fatal cancer each time 60 people are exposed to the maximum-allowable, annual occupational-radiation dose of $50 \mathrm{mSv} \cdot{ }^{20,21}$

US nuclear-waste policies in stages (8)-(9), radioactive waste transport/storage, likewise have already caused EIJ (as serious contamination at Hanford, Maxey Flats, Savannah River, and other cases have shown), and EIJ also is likely when future waste-containment canisters faillong before the million years that (the US National Academy of Sciences says) nuclear wastes must be completely secured. ${ }^{22}$ Because the US government has falsified and manipulated data on radioactive-waste risk ${ }^{22,23,24}$ (much of which will be borne by Appalachian, Latino, and Native-American populations, who live in higher proportions near existing and proposed nuclear-waste-storage sites), ${ }^{3}$ United Nations and nuclear-industry studies warn that the US government may underestimate future wasterepository-radiation doses by $9-12$ orders of magnitude. ${ }^{25}$ Yet even if proposed future US nuclear-waste standards are met, their leniency likely will impose EIJ on future generations. After 10,000 years, they would allow exposures of 100 millirems/year (limits 1,000 percent higher than current standards for US Department of Energy facilities). They also use only mean or average dose to assess regulatory compliance. This means that, provided that the average person's exposure is no more than 100 millirems, many other people would be allowed to receive higher, even fatal, doses. 8,26

\section{EIJ and siting the proposed Vogtle nuclear reactors}

In addition to EIJ associated with uranium mining, uranium-fuel milling/conversion/enrichment/fabrication, and waste transport/management, commercial reactor siting also may involve EIJ. That is, disproportionate numbers of reactors may be placed in African-American, Hispanic, minority, or poverty-level neighborhoods. Consider the Vogtle nuclear facility in Waynesboro, Georgia. In 2006 Southern Nuclear Operating Company (SNOC) proposed two additional reactors for Waynesboro. ${ }^{27} \mathrm{Cur}$ rently SNOC's Early Site Permit Application, ${ }^{28}$ as well as its Combined Construction Operating License, are under Nuclear Regulatory Commission review. ${ }^{29}$

Because SNOC uses at least three flawed criteria for assessing EIJ, it likely errs when it denies that the Vogtle facility causes EIJ for minority and poverty-level populations. ${ }^{30}$ According to these criteria, SNOC considers EIJ to exist only if (1) census blocks within the full, 50-mile radius of the facility include high minority/poverty-level populations; (2) these census blocks have either (a) greater-than-50-percent-minority / poor population, or (b) a minority/poor population that exceeds the averages for Georgia or South Carolina by at least 20 percentage points, ${ }^{31,32}$ and (3) the facility is located amid dense population. ${ }^{33}$ Consider (1)-(3) in order.

Criterion (1) arguably dilutes potential EIJ effects by using a 50-mile radius, ${ }^{31}$ instead of assessing closer minor- 
ity/poor populations. Obviously the greater the distance from a risky facility, the less likely are risks, therefore EIJ. Besides, the classic National Cancer Institute (NCI) study (of cancer rates near nuclear plants) says areas 30 (not 50) miles from a nuclear plant are those most likely to be affected by emissions. ${ }^{1,34}$ Criterion (1) also ignores wind patterns relative to minority/low-income census tracts; areas downwind of Vogtle would likely experience greater risks.

SNOC use of criteria (2)(a) and (2)(b) likewise are unrealistic and unfair. Regarding (2)(a)—which requires 50 percent minority/low-income population within a 50mile radius of Vogtle to show EIJ-consider that in the US, average state low-income populations range from 4.3 to 16 percent (Table 1 ). This means that showing incomerelated EIJ, under (2)(a), would require showing low-income populations (within 50 miles of Vogtle) that were 3-12 times greater than the state average (Table 1). Even a doubling of low-income groups near Vogtle would not count as EIJ, under criterion (2)(a). Regarding criterion (2)(b) - which requires minority/low-income populations 20 percentage points above Georgia or South Carolina averages, to show EIJ-Georgia and South Carolina already have minority populations of about 30 percent (Table 1 ). To show EIJ, criterion (2)(b) thus requires nearly doubling (over the state average) the percent-minority population residing near Vogtle.

Using these arguably unrealistic and unfair EIJ criteria (2)(a)-(2)(b), SNOC says 183 census-block groups (37.3 percent within a 50-mile radius of Vogtle) meet criterion (2)(a) for minority populations; 14 census-block groups (2.8 percent) meet criterion (2)(a) for poverty-level populations; 168 census-block groups (34.2 percent) meet criterion (2)(b) for minority populations; and 72 censusblock groups (14.7 percent) meet criterion (2)(b) for poverty-level populations. ${ }^{31}$ Using the preceding data and anecdotal evidence collected from two phone interviews, SNOC admits: "some existing communities within the [50-mile-radius] area exhibit disproportionately high percentages of minority (primarily Black races) and lowincome populations." 30 Because SNOC says these highdensity minority/low-income areas are "scattered," SNOC concludes that "there were no environmental justice effects to consider with respect to densely populated minority or low-income peoples." 30

As the preceding quotation reveals, EIJ criterion (3) of SNOC likewise is unrealistic and unfair because it recognizes only "densely-populated" minority/low income residents as EIJ victims. Yet whether EIJ victims live in sparsely-populated (rural), or densely-populated (urban) areas is logically irrelevant to whether they are EIJ victims of discrimination. Criterion (3) essentially excludes all rural cases of EIJ. Further bias in assessing EIJ is evident when SNOC uses EIJ criterion (3) and lists Augusta, Georgia (population 195,182$)^{35}$ as the nearest (26 miles away) population center to Vogtle. ${ }^{33}$ It defines "population center" as having greater than 25,000 residents, ${ }^{33}$ then claims the Vogtle facility is located in a sparsely populated area. ${ }^{33}$ This claim is questionable because Vogtle is directly located in largely-minority, largely low-income Waynesboro, Georgia, whose population is $5,813 .{ }^{36}$ Thus although Vogtle satisfies none of SNOC's three EIJ criteria, because all the criteria are scientifically suspect, siting the Vogtle reactors may well involve EIJ.

\section{Anecdotal evidence for EIJ in US nuclear siting}

Apart from questionable EIJ criteria used in the preceding Georgia case, does EIJ typify other US nuclear-siting cases? Consider the Grand Gulf Nuclear station, in Port Gibson, Mississippi. Some Mississippi citizens' groups claim this reactor was sited under EIJ conditions because its home-county population is 85 percent AfricanAmerican, and 33 percent poverty-level. ${ }^{1,9}$

On one hand, as Table 1 reveals, census data (from zip codes in which the 104 US nuclear facilities are located) suggest nuclear plants are often sited in zip codes having higher percentages of African-American/Hispanic/minority/poverty-level residents than is average for their home states. On the other hand, the fact that 42 of 104 zip codes (in which nuclear plants are located) have higher-than-average populations (of these EIJ victims) may not show that US commercial nuclear siting involves EIJ. Even without nuclear-related EIJ, one would expect half of the minority/low-income populations (in zip codes where roughly half (52) of US commercial nuclear reactors are located) to be above the state average, and roughly half below. Also, there is a timegap in the zip-code demographic data. These data are recent, while many nuclear plants were built 30-35 years ago, when vulnerable populations may not have lived nearby. Moreover, because Table 1 reveals nothing about how far above (or below) average are the percentages of vulnerable populations living near nuclear plants, it provides little reliable evidence regarding EIJ.

\section{Types of, and conditions for, nuclear-siting-related EIJ}

To provide a more reliable, preliminary assessment of possible EIJ in commercial nuclear-reactor siting, we first categorized at least four types of EIJ. EIJA, EIJH, EIJM, and EIJP refers to EIJ that impacts, respectively, AfricanAmericans, Hispanics, minorities, and poverty-level residents. ("Minority" refers to any individual who does not self-identify as "white" in the national census.)

We define EIJA, EIJH, EIJM, and EIJP, respectively, as instances in which at least two necessary conditions are met: (1) the percentage of the population that is, respectively, African-American, Hispanic, minority, and poverty-level, in a given nuclear-reactor geographic area (zip code or census tract), is higher than the respective average-percentage for the state in which the reactor is located, and (2) statistical data show that these higher percentages are unlikely to be due purely to chance. Providing a preliminary statistical assessment of nuclear-sitingrelated EIJ, this article examines (1) and (2).

\section{Zip-code-scale and census-tract-scale statistical evidence regarding nuclear-siting-related EIJ}

Each potential instance of EIJ (EIJA, EIJH, EIJM, EIJP) was analyzed using z-tests and/or paired t-tests to compare individual zip-code demographic data (on minor- 


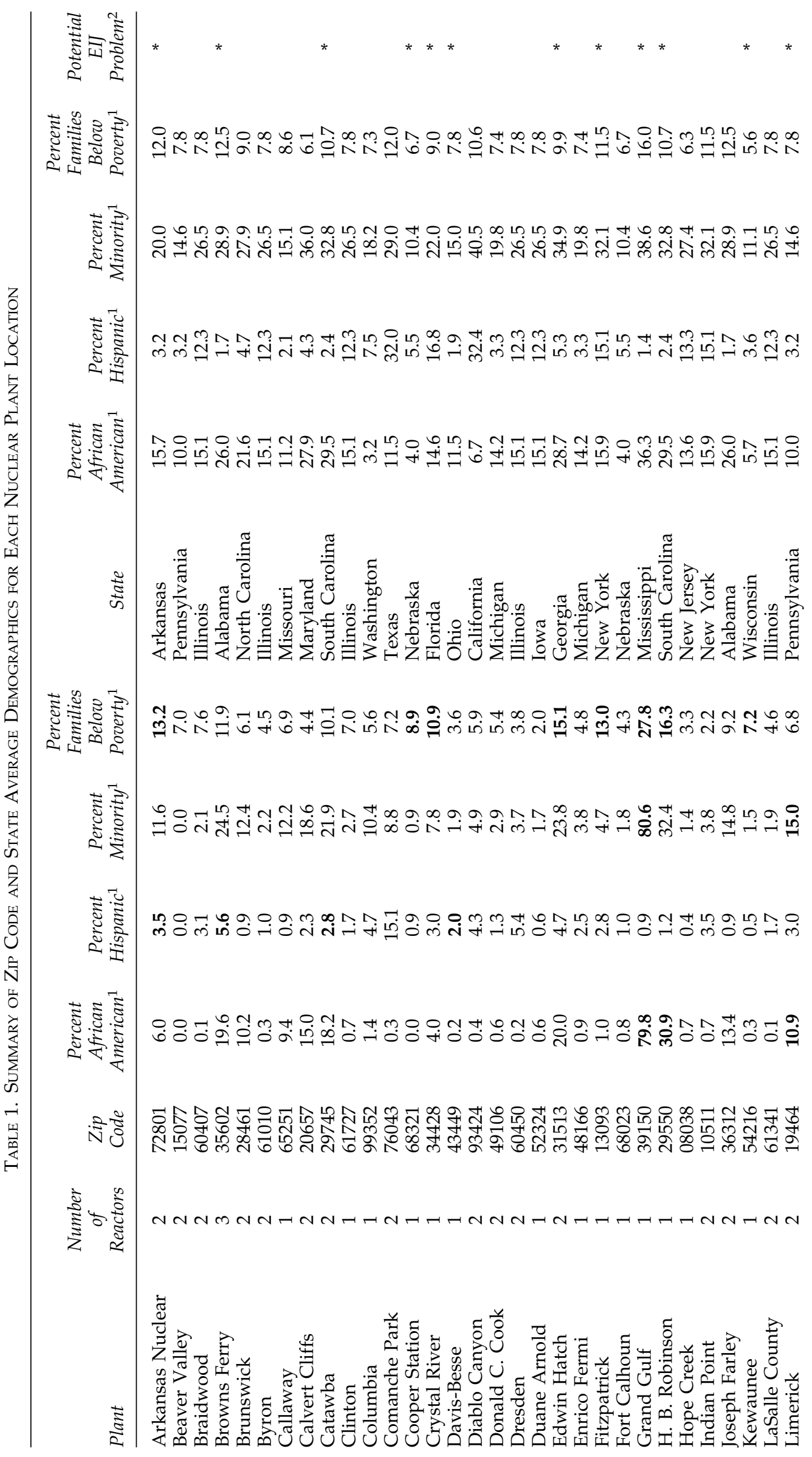




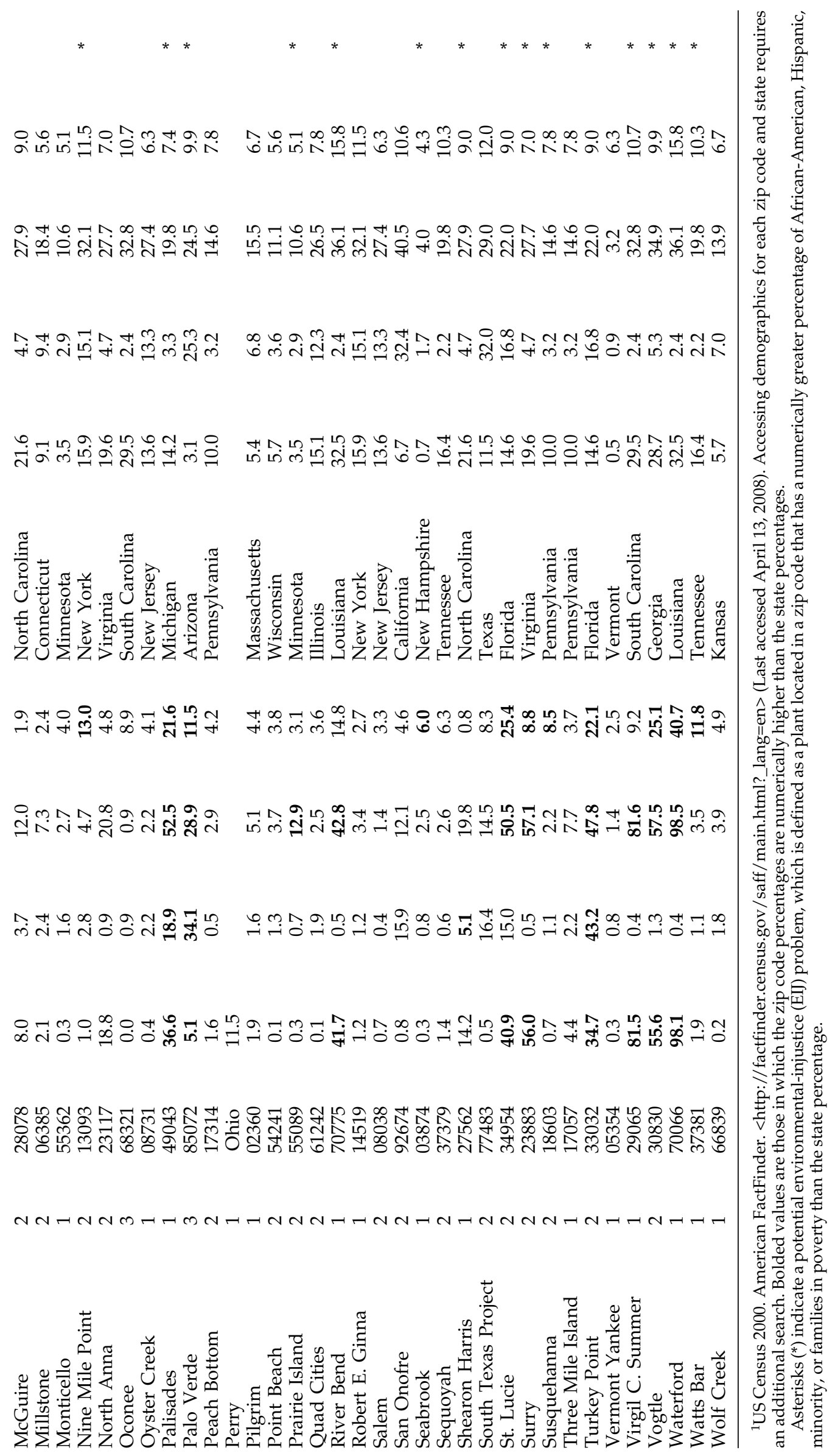


ity/low-income populations) to the state-average data (Table 1); each US commercial reactor constituted a replicate $(\mathrm{N}=104)$. Based on t-tests and census data, nuclearrelated, zip-code-scale EIJ (EIJA/EIJH/EIJM/EIJP) is not obvious, at least not on a national scale (Table 2 ).

Concerned that geographical dilution could cause the apparent absence of reactor-related, zip-code-scale EIJ (because including more-distant, less-affected population areas often tends to dilute apparent-EIJ effects, as may have occurred with SNOC criterion (1)), ${ }^{31}$ we repeated the same paired t-tests, at a closer-to-facility, census-tract scale (Table 3). These census-tract-scale data likewise showed no obvious national EIJA, EIJH, EIJM, or EIJP (Table 4).

\section{Regional-scale evidence regarding nuclear-siting- related EIJ}

Because many more potential nuclear-EIJ sites are located in the southeastern United States (Tables 1, 3), we also analyzed zip-code data by region (Table 5). These regions are defined as follows. The Southeast includes all commercial reactors located in Arkansas, Alabama, North Carolina, South Carolina, Georgia, Florida, Mississippi, Virginia, Louisiana, and Tennessee. The Northeast includes all those located in Pennsylvania, Maryland, New York, New Jersey, Connecticut, Massachusetts, New Hampshire, and Vermont. The Midwest includes all facilities located in Illinois, Ohio, Michigan, Wisconsin, Iowa, and Minnesota. The West (of the Mississippi) includes all facilities located in Missouri, Washington, Texas, Nebraska, California, Arizona, and Kansas.

Paired t-test, zip-code analyses, by regions, show that only the Southeast (with 38 reactors) appears to have potential instances of EIJP (Fig. 1); no EIJA, EIJH, or EIJM are obvious. However, Table 5 shows that, given the caveat that year-2000 census-data demographics accurately represent demographics at the time of reactor siting, at least in southeastern United States, zip-code-scale data and t-tests suggest that commercial, reactor-sitingrelated EIJP has a 77-percent likelihood of not being due merely to chance $(p=0.23)$. Even more important results are that, given the preceding caveat, more sensitive zipcode and z-test data show that in the Southeast, commercial, reactor-siting-related EIJP has greater-than-99percent likelihood of not being due merely to chance $(p<$ 0.001) (Table 5).
However, statistically significant, reactor-related EIJP does not appear to occur at the census-tract scale in the Southeast, and no instance of EIJ was evident at the censustract scale within any region (Table 6). Although further research is needed to clarify these census-tract data, their not revealing apparent EIJ may result from the fact that, as the US Census Bureau puts it, census tracts "are designed to be homogenous with respect to population characteristics, economic status and living conditions. ${ }^{\prime 37}$ Drawing census-tract boundaries so as to ensure homogeneity would make EIJ (and its associated racial or economic heterogeneities and inequities) less likely to appear at the census-tract scale. Nevertheless, the census-tract results are interesting because EIJ typically is more evident at a closer-to-facility (census-tract) scale than at a larger scale. In this analysis, EIJP appears only at the larger zip-code scale.

Interestingly, over 36 percent of US nuclear reactors are located in the Southeast, 25 percent in the Northeast, 23 percent in the Midwest, and 15 percent in the West. However, census data show that the Southeast contains only about 26 percent of US population, while the Northeast has 23 percent; the Midwest, 19 percent; and the West, 31 percent. Given the preceding caveat, if the percentage of commercial reactors in each region were proportional to its population, we would expect to find only 26 (not 36) percent of reactors in the Southeast. This means the number of Southeast reactors is 38 percent greater than expected-a disproportionately high percentage of commercial reactors, given the regional population and the preceding caveat. In comparison, reactor numbers are only 7 percent greater than expected in the Northeast and 19 percent greater in the Midwest. Reactor numbers are 52 percent less than expected in the West. The preceding data suggest that the Southeast may be bearing more of a nuclear-reactor burden than the rest of the nation.

\section{CONCLUSIONS}

The preceding discussion suggests that although census-tract-scale data indicate no obvious EIJA, EIJH, EIJM, or EIJP associated with US nuclear-reactor siting, perhaps because of the way census-tract boundaries are intentionally drawn, that is not the whole story. Given the preceding caveat that year-2000 census data reasonably estimate demographics at the time of reactor siting, zip-code-scale data and z-tests reveal apparent reactor-

Table 2. Z-Tests and Paired t-Tests Comparing Percent Demographic Compositions of Zip Codes Containing Nuclear Reactors to the State Averages for the Same Demographic Compositions

\begin{tabular}{lccrr}
\hline & African American & Hispanic & Minority & Families Below Poverty \\
\hline $\mathrm{t}_{103}$ & -5.932 & -9.997 & -6.685 & -2.558 \\
$\mathrm{p}$ & $<0.001$ & $<0.001$ & $<0.001$ & 0.012 \\
$\mathrm{Z}_{104}$ & -10.777 & -7.084 & -14.392 & -5.531 \\
$\mathrm{p}$ & $<0.001$ & $<0.001$ & $<0.001$ & $<0.001$ \\
\hline
\end{tabular}

Each $t_{x}$ represents the $t$-value of a paired $t$-test with $x$ degrees of freedom.

Each $Z_{n}$ represents the $Z$ value of a one-sample $Z$-test with $n$ cases.

Percentage data were arcsine-square-root transformed prior to statistical testing. 


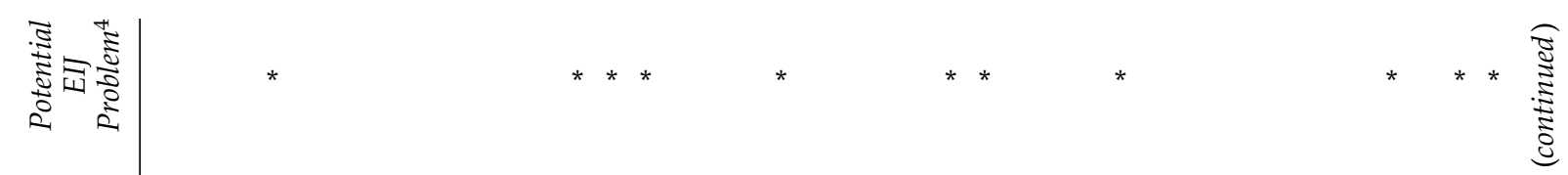

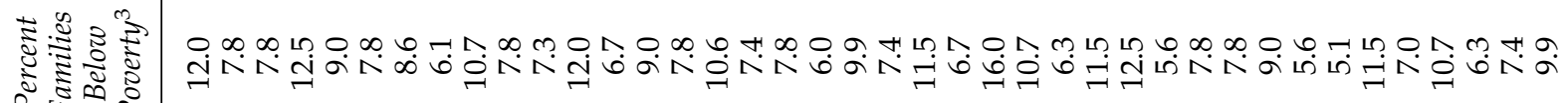

氝.

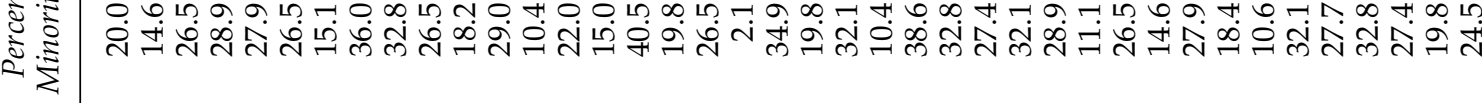

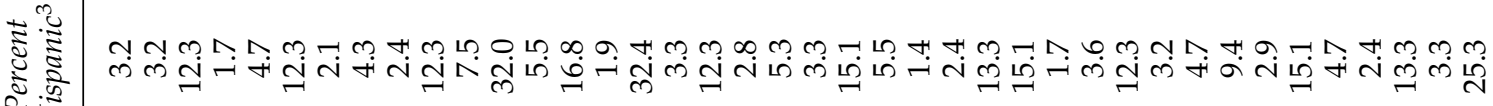

$2 \cdot$ 这

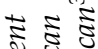

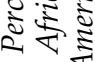

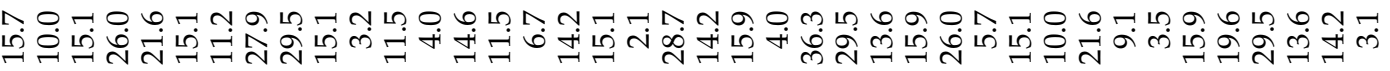

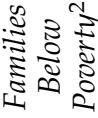

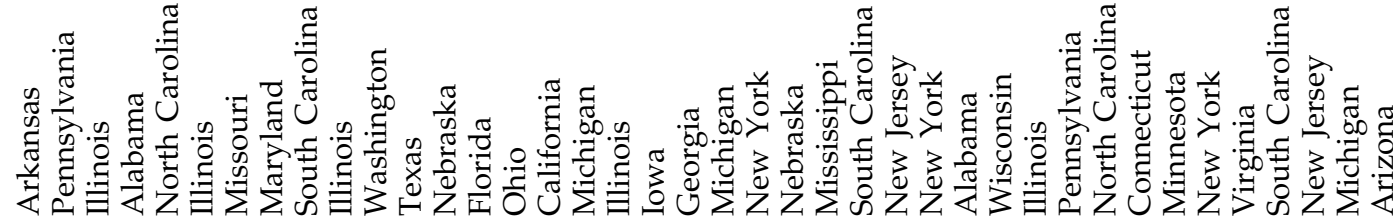

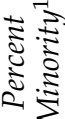

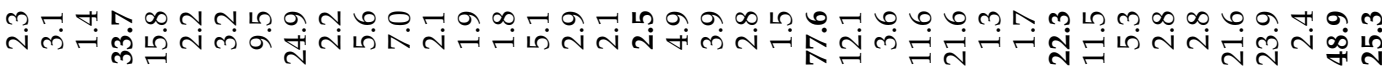

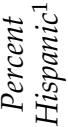

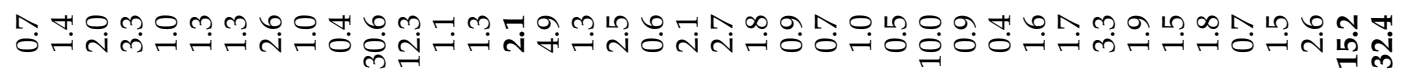

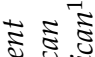

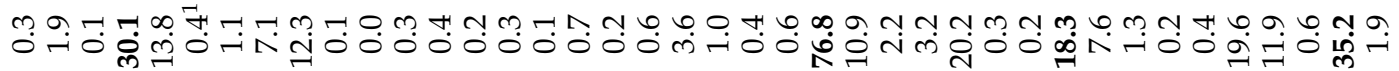

$\stackrel{\frac{1}{2}}{2}$

تூ

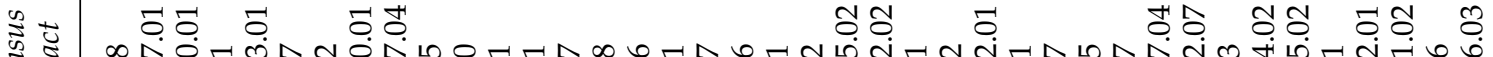

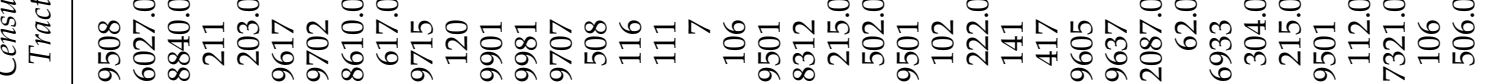

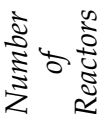

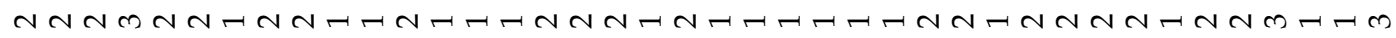

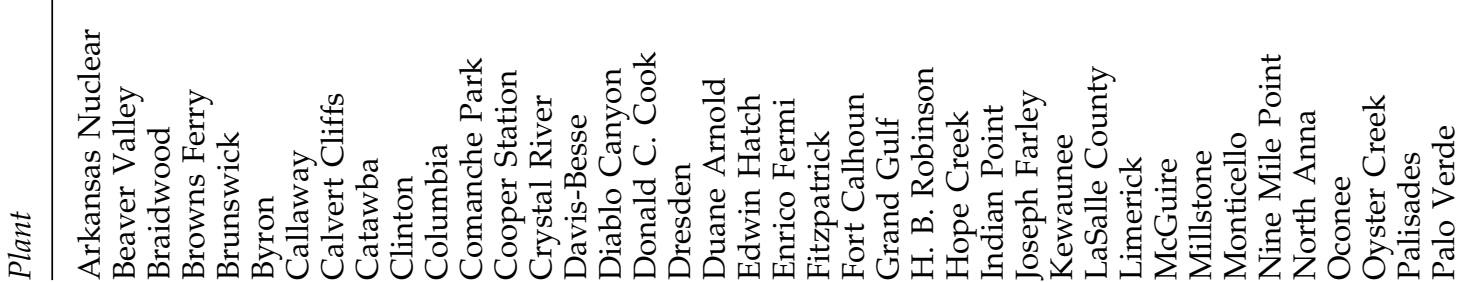




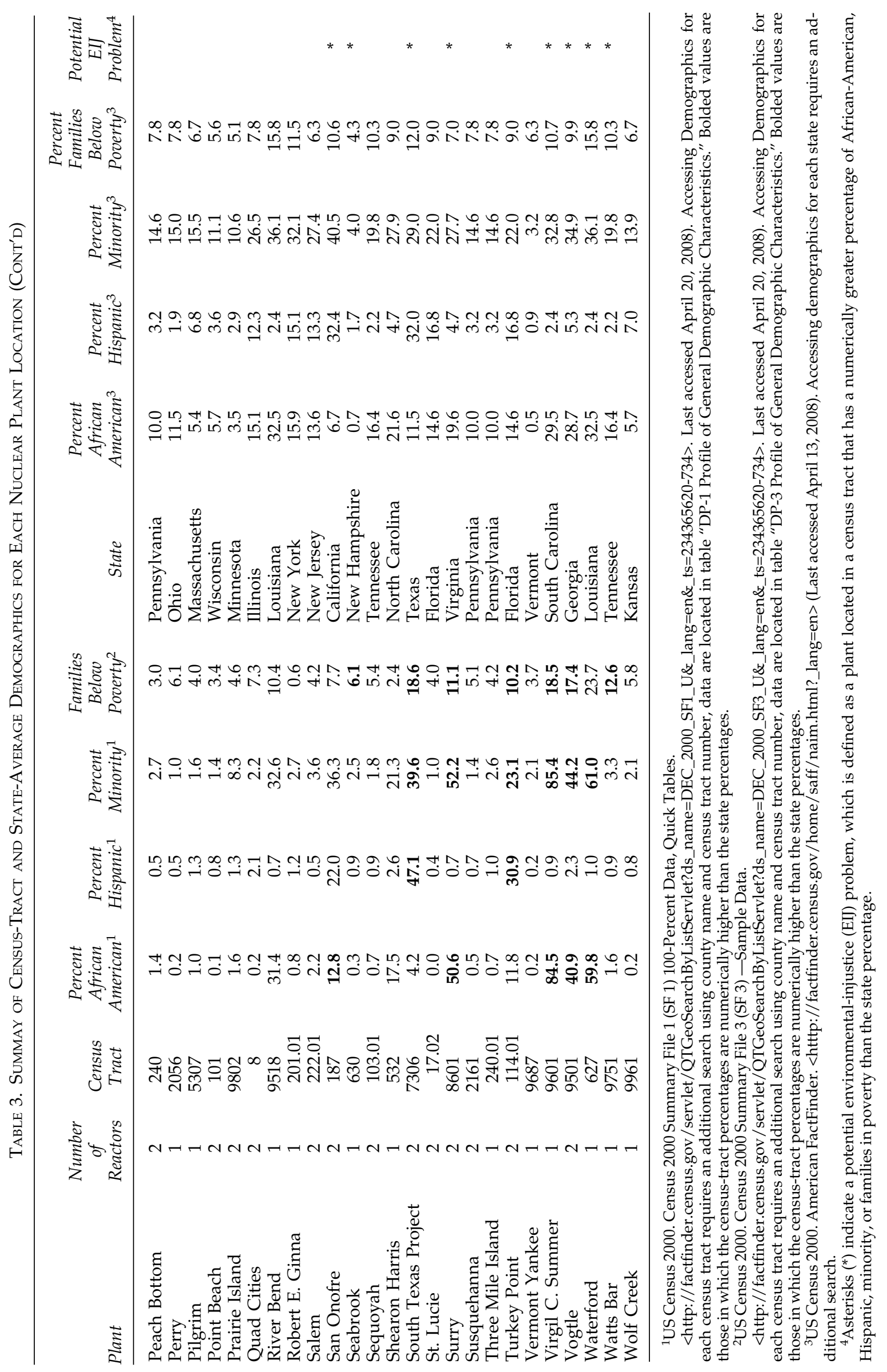


Table 4. Z-Tests and Paired t-Tests Comparing Percent Demographic Compositions of Census Tracts Containing Nuclear Reactors to the State Averages for the Same Demographic Compositions

\begin{tabular}{lcccc}
\hline & African American & Hispanic & Minority & Families Below Poverty \\
\hline $\mathrm{t}_{103}$ & -7.742 & -8.572 & -8.058 & -4.666 \\
$\mathrm{p}$ & $<0.001$ & $<0.001$ & $<0.001$ & $<0.001$ \\
$\mathrm{Z}_{104}$ & -12.077 & -7.736 & -13.394 & -10.680 \\
$\mathrm{p}$ & $<0.001$ & $<0.001$ & $<0.001$ & $<0.001$ \\
\hline
\end{tabular}

Each $t_{x}$ represents the $t$-value of a paired $t$-test with $x$ degrees of freedom.

Each $Z_{n}$ represents the $Z$ value of a one-sample $Z$-test with $n$ cases.

Percentage data were arcsine-square-root transformed prior to statistical testing.

Table 5. Z-Tests and Paired t-Tests Comparing Percent Demographic Compositions of Zip Codes Containing Nuclear Reactors to the State Averages for the Same Demographic Compositions within Each Geographical Region

\begin{tabular}{|c|c|c|c|c|c|}
\hline Region & & African American & Hispanic & Minority & Families Below Poverty \\
\hline \multirow[t]{2}{*}{ Midwest } & $t_{23}$ & -8.788 & -4.960 & -6.376 & -3.406 \\
\hline & $\mathrm{p}$ & $<0.001$ & $<0.001$ & $<0.001^{2}$ & 0.002 \\
\hline \multirow[t]{2}{*}{ Northeast } & $\mathrm{t}_{25}$ & -9.323 & -7.700 & -9.205 & -4.258 \\
\hline & $\mathrm{p}$ & $<0.001$ & $<0.001$ & $<0.001$ & $<0.001$ \\
\hline \multirow[t]{4}{*}{ Southeast } & $\mathrm{t}_{37}$ & -0.317 & -1.847 & -0.471 & 1.228 \\
\hline & $\mathrm{p}$ & 0.753 & 0.073 & 0.640 & 0.227 \\
\hline & $\mathrm{Z}_{38}$ & -1.269 & -2.152 & -2.281 & 3.880 \\
\hline & $\mathrm{p}$ & 0.205 & 0.031 & 0.023 & $<0.001$ \\
\hline \multirow[t]{2}{*}{ West } & $t_{15}$ & -3.224 & -3.668 & -4.397 & -3.709 \\
\hline & $\mathrm{p}$ & 0.005 & 0.002 & 0.001 & 0.002 \\
\hline
\end{tabular}

Each $t_{x}$ represents the $t$-value of a paired $t$-test with $x$ degrees of freedom.

Each $Z_{n}$ represents the $Z$ value of a one-sample $Z$-test with $n$ cases.

Percentage data were arcsine-square-root transformed prior to statistical testing.

Significant positive results are shown in bold.

Table 6. Z-Tests and Paired t-Tests Comparing Percent Demographic Compositions of Census Tracts Containing Nuclear Reactors to the State Averages for the Same Demographic Compositions within Each Geographical Region

\begin{tabular}{llccrr}
\hline Region & & African American & Hispanic & Minority & Families Below Poverty \\
\hline Midwest & $\mathrm{t}_{23}$ & -8.319 & -5.504 & -7.258 & -3.469 \\
\multirow{3}{*}{ Northeast } & $\mathrm{p}$ & $<0.001$ & $<0.001$ & $<0.001^{2}$ & 0.002 \\
& $\mathrm{t}_{25}$ & -8.161 & -7.394 & -8.696 & -3.263 \\
Southeast & $\mathrm{p}$ & $<0.001$ & $<0.001$ & $<0.001$ & 0.003 \\
& $\mathrm{t}_{37}$ & -1.468 & -4.722 & -1.453 & -1.687 \\
& $\mathrm{p}$ & 0.151 & $<0.001$ & 0.155 & 0.100 \\
\multirow{2}{*}{ West } & $\mathrm{Z}_{38}$ & -5.187 & -5.066 & -6.033 & -4.315 \\
& $\mathrm{p}$ & $<0.001$ & $<0.001$ & $<0.001$ & $<0.001$ \\
& $\mathrm{t}_{15}$ & -6.289 & -1.663 & -3.899 & -1.258 \\
\hline
\end{tabular}

Each $t_{x}$ represents the $t$-value of a paired $t$-test with $x$ degrees of freedom.

Each $Z_{n}$ represents the $Z$ value of a one-sample $Z$-test with $n$ cases.

Percentage data were arcsine-square-root transformed prior to statistical testing. 
A

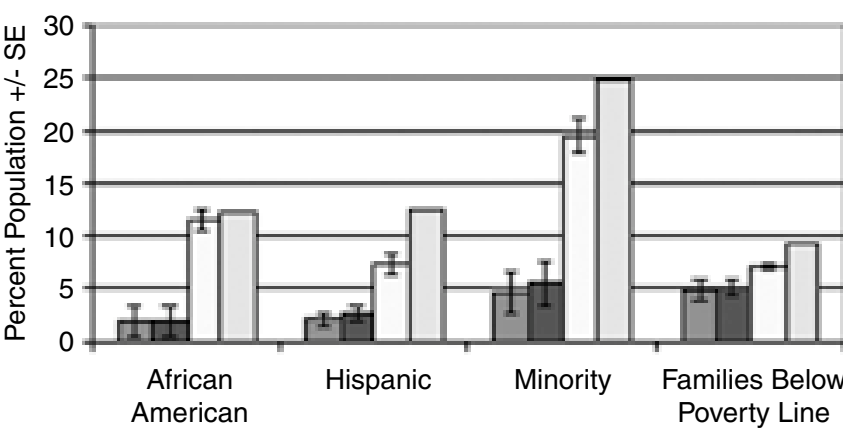

B

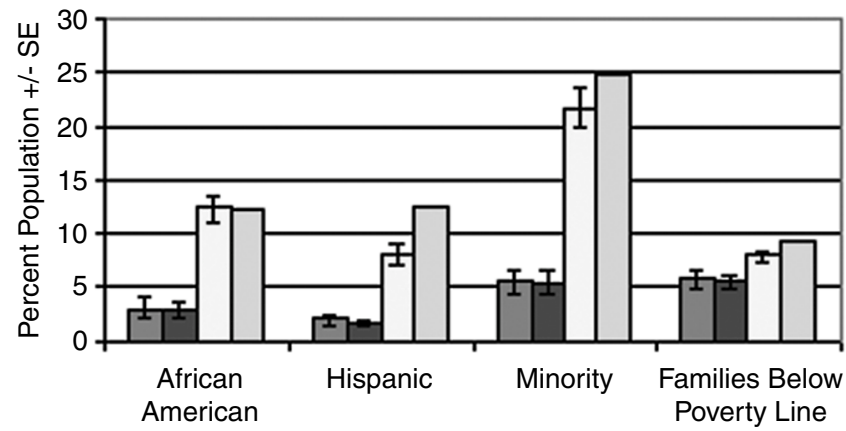

C

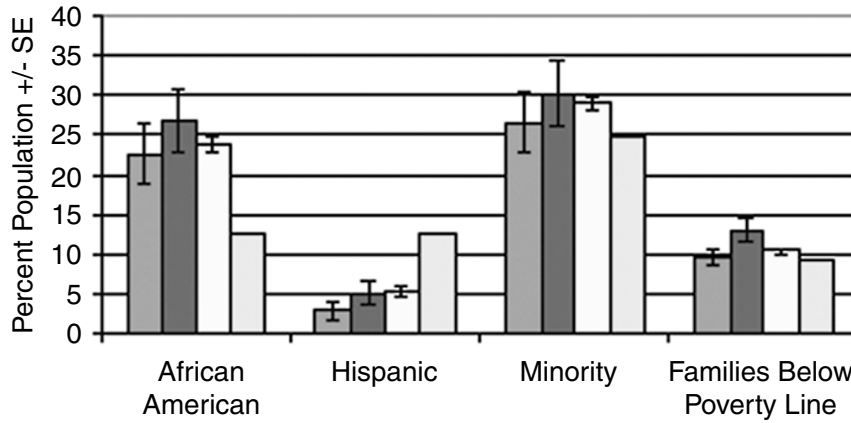

D

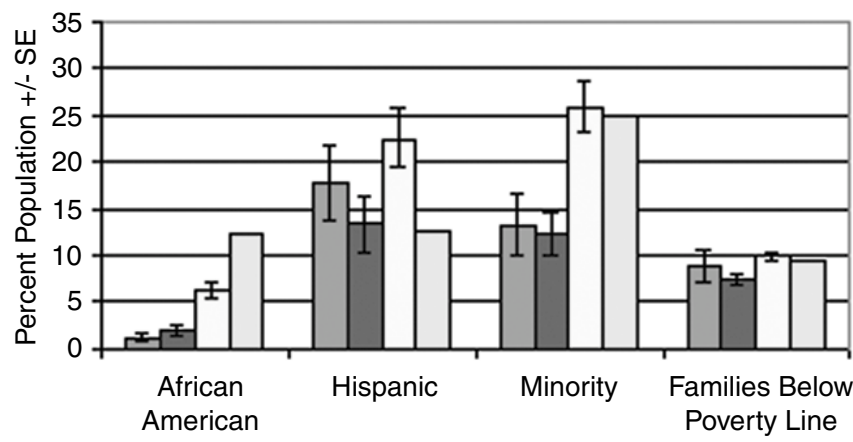

aCensus Tract Average aZip Code Average o State Average cunited States Average $\square$ Census Tract Average $\square$ Zip Code Average $\square$ State Average 口United States Average $\square$ Census Tract Average $\square$ Zip Code Average $\square$ State Average $\square$ United States Average

\section{$\square$ Census Tract Average}

$\square$ Zip Code Average

$\square$ State Average

$\square$ United States Average

FIG. 1. Demographic data for zip codes and census tracts in which nuclear reactors are located, within each geographical region, compared to both state average demographics and national average demographics. A. Midwest communities. B. Northeast communities. C. Southeast communities. D. West communities. Error bars show standard error $(\mathrm{SE})$.

siting-related EIJP, affecting poverty-level people in the Southeast $(p<0.001)$.

These EIJP findings are interesting, given much higherthan-expected numbers of commercial reactors, and a disproportionately higher percentage of both African-Ameri- cans and poverty-level populations, in the southeastern US than in other regions of the country. ${ }^{38}$ These considerations suggest that future studies may need to consider both possible commercial-reactor-related, regional (southeastern) EIJ affecting African-American and poverty-level popula- 
tions and EIJ that may have occurred at the time of reactor siting, as revealed in year-1960, -1970, -1980, and -1990 census data.

\section{REFERENCES}

1. Joseph J. Mangano, “Excess Infant Mortality after Nuclear Plant Startup in Rural Mississippi," International Journal of Health Services 38 (2008): 277-291.

2. Claudia Spix, "Do Nuclear Plants Boost Leukemia Risk?" New Scientist 2642 (February 12, 2008): 6.

3. Shrader-Frechette, Kristin. Environmental Justice: Creating Equality, Reclaiming Democracy. (New York, Oxford University Press, 2002), 158.

4. Joseph J. Mangano, "Infant Death and Childhood Cancer Reductions after Nuclear Plant Closings in the United States," Archives of Environmental Health 57 (January-February 2002): 23-31.

5. Joseph J. Mangano, "Improvements in Local Infant Health after Nuclear Power Reactor Closing," Environmental Epidemiology and Toxicology 2 (January-March 2000): 32-36.

6. Wing, S., D. Richardson, D. Armstrong, and D. Crawford-Brown, "A Re-evaluation of Cancer Incidence near the Three Mile Island Nuclear Plant," Environmental Health Perspectives 105 (January 1997): 53-57.

7. National Research Council. Biological Effects of Ionizing Radiation VII, (Washington DC, National Academy Press, 2005), 6 .

8. United Nations Scientific Committee on Effects of Atomic Radiation. Sources, Effects, and Risks of Ionizing Radiation. (New York, United Nations, 1994).

9. Kyle Rabin, "Indian Point's Owner Played Role in Attacks on Environmental Justice," (Press Release, Nuclear Information and Resource Service, February 25, 2004).

10. Daniel Weisser, "A Guide to Life-Cycle Greenhouse Gas (GHG) Emissions from Electric Supply Technologies," Energy 32 (September 2007): 1543-1559.

11. U.S. Advisory Committee on Human Radiation Experiments. Human Radiation Experiments Associated with the U.S. Department of Energy and Its Predecessors. (Washington DC, US Department of Energy, July 1995).

12. Center for World Indigenous Studies. The Fourth World Documentation Project (Olympia, Washington, CWIS, 1999).

13. World Information Service on Energy. Uranium Mining and Indigenous People. <http://www.wise-uranium. org/uip.html >. (Last accessed on June 30, 2008).

14. Jonathan M. Samet, D. M. Kutvirt, R. J. Waxweiler, and C. R. Key, "Uranium Mining and Lung Cancer in Navajo Men," New England Journal of Medicine 310 (June 7,1984): 1481-1484.

15. Navajo Nation Council. The Dine Natural Resources Protection Act of 2005. <http://www.sric.org/uranium/ DNRPA.pdf $>$. (Last accessed on June 30, 2008).

16. U.S. National Institute for Occupational Safety and Health. Energy-Related Health Research Program. (Washington DC, US NIOSH, 2001). <http://www.cdc.gov/niosh/2001133a.html $>$. (Last accessed on October 16, 2005).

17. U.S Code of Federal Regulations. Standards for Protection against Radiation. (Washington DC, National Archives and Records Administration, 2005), Title 10, Part 20, sec- tions 1201 and 1301. <http://www.access.gpo.gov/ nara/cfr/waisidx_00/10cfr20_00.html>. (Last accessed on September 1, 2008).

18. U.S. Congress, House Committee on Commerce, 106th Cong., 1st sess., 1999, Hearing 106-43. < http://frwebgate. access.gpo.gov/cgi-bin/getdoc.cgi?dbname $=106$ house_hearings\&docid $=\mathrm{f}: 58494 . \mathrm{pdf}>$. (Last accessed on September 1, 2008).

19. U.S. General Accounting Office. Report GAO/RCED-98163: Department of Energy: Clear Strategy on External Regulation Needed for Worker and Nuclear Facility Safety. (Washington DC, US GAO, May 1998). <http://www. gao.gov/archive/1998/rc98163.pdf $>$. (Last accessed on September 1, 2008).

20. Kristin Shrader-Frechette, "Trimming Exposure Data, Putting Radiation Workers at Risk: Improving Disclosure and Consent through a National Radiation Dose Registry," American Journal of Public Health 97 (August 29, 2007): 1782-1786.

21. Elisabeth Cardis et al., "Risk of Cancer after Low Doses of Ionising Radiation: Retrospective Cohort Study in 15 Countries," British Medical Journal 331 (July 9, 2005): 77-80.

22. Kristin Shrader-Frechette. Burying Uncertainty: Risk and the Case against Geological Disposal of Nuclear Waste. (Berkeley, University of California Press, 1993), 4-6, 69-71, 79-89, 53-57, 161, 169; National Research Council. Technical Bases for Yucca Mountain Standards. (National Academy Press, 1994).

23. Naomi Lubick, "Falsification Alleged at Yucca Mountain," Geotimes 50 (May 2005): 10-11.

24. U.S. General Accounting Office. GAO-02-765T: Nuclear Waste: Uncertainties About the Yucca Mountain Repository Project. (Washington DC, US GAO, May 2002). <http:// www.gao.gov/new.items/d02765t.pdf $>$. (Last accessed on September 1, 2008).

25. International Atomic Energy Agency and the Organisation for Economic Co-Operation and Development. An International Peer Review of the Yucca Mountain Site Characterization Project. (Paris, Nuclear Energy Agency, 2001).

26. US Environmental Protection Agency. 40CFR Part 197: Public Health and Environmental Radiation Protection Standards for Yucca Mountain, Nevada. (Washington, DC: US Government Printing Office, 2008); Kristin ShraderFrechette, "Mortgaging the Future: Dumping Ethics with Nuclear Waste," Science and Engineering Ethics 11 (December 2005): 518-520.

27. Southern Nuclear Operating Company. Draft Environmental Impact Statement for an Early Site Permit (ESP) at the Vogtle Electric Generating Plant Site (NUREG-1872) Draft Report for Comment. Chapter 4: 59. <http:// www.nrc.gov/reading-rm/doc-collections/nuregs/staff/ sr1872/index.html $>$. (Last accessed on July 17, 2008).

28. US Nuclear Regulatory Commission. Early Site Permits-Southern Nuclear Operating Company Application for the Vogtle ESP Site. <http://www.nrc.gov/ reactors/new-licensing/esp/vogtle.html\#schedule $>$. (Last accessed on July 17, 2008).

29. US Department of Energy. Nuclear Plant Deployment Scorecard. <http://www.ne.doe.gov/np2010/neScorecard/neScorecard_col.html $>$. (Last accessed on July 17, 2008).

30. Southern Nuclear Operating Company. Draft Environmental Impact Statement for an Early Site Permit (ESP) at 
the Vogtle Electric Generating Plant Site (NUREG-1872) Draft Report for Comment. Chapter 4: 59. <http://www. nrc.gov/reading-rm/doc-collections/nuregs/staff/ sr1872/index.html >. (Last accessed on July 17, 2008).

31. SNOC uses NRC guidelines stated in US Nuclear Regulatory Commission, NRR Office Instruction No. LIC-203, Revision 1, Procedural Guidance for Preparing Environmental Assessments and Considering Environmental Issues, 24 May 2004. <http://www.nrc.gov/reactors/ operating/licensing/renewal/introduction/introductionfiles/lic-203rev1.pdf $>$ (Last accessed on September 1, 2008).

32. Southern Nuclear Operating Company. Draft Environmental Impact Statement for an Early Site Permit (ESP) at the Vogtle Electric Generating Plant Site (NUREG1872) Draft Report for Comment. Chapter 2.5: 26-28. <http://www.nrc.gov/reading-rm/doc-collections / nuregs/staff/sr1872/index.html $>$. (Last accessed on July 17, 2008).

33. Southern Nuclear Operating Company. Draft Environmental Impact Statement for an Early Site Permit (ESP) at the Vogtle Electric Generating Plant Site (NUREG1872) Draft Report for Comment. Chapter 2.1: 1. <http://www.nrc.gov/reading-rm/doc-collections / nuregs/staff/sr1872/index.html $>$. (Last accessed on July 17, 2008).

34. Seymour Jablon, "Cancer in Populations Living Near Nuclear Facilities," Journal of the American Medical Association 265 (March 1990): 1403.

35. U.S. Census 2000. "Augusta city, Georgia." American FactFinder. <http://factfinder.census.gov/servlet/SAFF
Facts?_event $=\& g e o \_i d=16000 U S 1304204 \&$ \&eoContext $=01000 U S \% 7 C 04000 U S 13 \% 7 C 16000 U S 1304204 \&$ \&street $=\& \_$county $=$Augusta\&_cityTown $=$Augusta\&_state $=$ 04000US13\&_zip =\&_lang $=$ en\&_sse $=$ on\&ActiveGeo$\operatorname{Div}[=\mathrm{t}] \& \_u s e E V=\& \mathrm{pctxt}=\mathrm{fph} \& \mathrm{pgsl}=160 \& \_$submenuId $=$ factsheet_1\&ds_name $=$ ACS_2006_SAFF\&_ci_nbr $=$ null $\& q r \_$name $=$null $\&$ reg $=\& \_$keyword $=\& \_$industry $=>$. (Last accessed on April 13, 2008).

36. U.S. Census 2000. "Waynesboro city, Georgia." American FactFinder. <http://factfinder.census.gov/servlet/SAFF Facts?_event $=$ Search\&geo_id=\&_geoContex $\mathrm{t}=$ \&_street $=\& \_$county $=$Waynesboro\&_cityTown $=$Waynesboro \&_state $=04000$ US13\&_zip $=$ \&_lang $=$ en\&_sse $=$ on\& pctxt $=$ fph\&pgsl $=010 \&$ show_2003_tab $=$ \&redirect $=Y>$. (Last accessed on April 13, 2008).

37. U.S. Census Bureau. Census Tracts and Block Numbering Areas. <http://www.census.gov/geo/www/cen_ tract.html $>$. (Last accessed on August 29, 2008).

38. Richard Morrill, "Geographic Variation in Change in Income Inequality among US States, 1970-1990," The Annals of Regional Science 34 (March 2000): 109-130.

Address correspondence to: Kristin Shrader-Frechette Department of Biological Sciences and Department of Philosophy 100 Malloy Hall, University of Notre Dame Notre Dame, IN 46556

E-mail: kshrader@nd.edu 